\title{
LADLE FURNACE SLAG REPLACEMENT ON THE FLEXURAL STRENGTH OF THIN FLY ASH GEOPOLYMER
}

\author{
Ng YONG-SING ${ }^{1}$, Liew YUN-MING ${ }^{1, *}$, Mohd Mustafa Al Bakri ABDULLAH ${ }^{1}$, \\ Ng HUI-TENG ${ }^{1}$, Ridho BAYUAJI² \\ ${ }^{1}$ Center of Excellence Geopolymer and Green Technology (CEGeoGTech), School of Materials Engineering, \\ Universiti Malaysia Perlis (UniMAP), 01000 Kangar, Perlis, Malaysia \\ ${ }^{2}$ Civil Engineering Department, Institut Teknologi Sepuluh Nopember, Indonesia
}

\begin{abstract}
This article reports the investigation on the effect of ladle furnace slag replacement on the flexural strength of thin fly ash-based geopolymer. The thin fly ash/slag geopolymers were prepared with the replacement of various percentages of ladle furnace slag $(0 \%, 10 \%, 20 \%$, $30 \%$ and $40 \%$ ) into fly ash geopolymers with dimension of $160 \mathrm{~mm} \times 40 \mathrm{~mm} \times 10 \mathrm{~mm}$. The thin geopolymer was synthesised using $12 \mathrm{M}$ sodium hydroxide $(\mathrm{NaOH})$ solution with solid-to-liquid $(\mathrm{S} / \mathrm{L})$ ratio of 2.5 and $\mathrm{Na}_{2} \mathrm{SiO}_{3} / \mathrm{NaOH}$ ratio of 4.0. The curing temperature and time of samples were $60^{\circ} \mathrm{C}$ and 6 hours respectively. The mechanical properties of thin geopolymers was revealed using flexural test after 28 days. Several characterisation tools have been used including Scanning Electron Microscope (SEM) and X-Ray Diffraction (XRD) to correlate the flexural properties with the microstructure and phases of fly ash/slag geopolymers. Results obtained reported that a positive effect on flexural strength was observed with the increasing amount of slag. The thin fly ash geopolymers replaced with $40 \%$ of ladle furnace slag showed the highest flexural strength of 7.8 MPa. The rich $\mathrm{CaO}$ content in ladle furnace slag boosted the $C-S-H$ gels formation which increased the flexural strength of thin geopolymers.
\end{abstract}

Keywords: thin geopolymer, ladle furnace slag, replacement, fly ash, flexural strength.

\section{Introduction}

Geopolymers are inorganic polymers with $\mathrm{SiO}_{4}$ and $\mathrm{AlO}_{4}$ frameworks. They are produced by mixing aluminosilicates and alkaline silicate solution [1]. The solid aluminosilicate precursors could be categorised into two types such as industrial by-products (fly ash and slag) and natural materials (kaolin and metakaolin) [2]. The mixed aluminosilicates and alkaline silicate produced a short-range ordered amorphous gel arranged in three-dimensional structure exhibits excellent physical and mechanical properties [3]. Besides, geopolymers are environmental friendly with low energy consumption production process and low carbon footprint [4].

The flexural strength of thin fly ash geopolymers could be improved by incorporating slag as the aluminosilicate source during the mixing process. Slag is rich in $\mathrm{CaO}$ content and the $\mathrm{Ca}^{2+}$ from slag favours the formation of C-S-H (Calcium Silicate Hydrate) and C-(A)-S-H (Calcium Aluminosilicate Hydrate) gels which increased the mechanical properties and durability of geopolymers [5]. Sankar et al. [6] investigated the mechanical strength of slag-fly ash based geopolymers and reported that as the slag/fly ash ratio increased, the strength development of geopolymer was accelerated due to the formation of $\mathrm{C}-\mathrm{S}-\mathrm{H}$ gels and $\mathrm{C}-(\mathrm{A})-\mathrm{S}-\mathrm{H}$ gels in the structure of geopolymer which results in the formation of $\mathrm{Ca}$ - and $\mathrm{Na}$-based geopolymer. Chi and Huang [7] investigated the relationship of different sets of fly ash/slag ratios with the binding mechanism and properties of fly ash/slag geopolymers. Their results showed that the fly ash/slag 
ratio plays a significant role in affecting the binding mechanism and properties of geopolymers. Puligilla et al. [8] investigated the role of slag in fly ash/slag based geopolymers and observed that the reaction products were mainly dominated by $\mathrm{C}-\mathrm{S}-\mathrm{H}$ gel which coexisted with the aluminosilicate geopolymeric gels. This caused the setting time for geopolymerisation was shortened and increased the mechanical strength of geopolymers.

Thus far, researches regarding the flexural properties of geopolymers are mainly focused on precast concrete elements such as beams, columns. In comparison, flexural properties of thin neat (without addition of fillers or aggregates) geopolymers is less explored. Moreover, past studies reported that the flexural strength of geopolymers were always low (<20 MPa) in comparison with its compressive strength [9]. Therefore, this knowledge gap should be filled to further explore the field of utilisation of thin geopolymers in terms of flexural properties.

Ground-granulated blast furnace slag (GGBFS) was more well-known slag used in the geopolymers' research. However, in this study, ladle furnace slag (LFS) is proposed to be incorporated into the fly ash geopolymers as it possesses similar chemical composition (high calcium content) to GGBFS. The smaller particles size of ladle furnace slag could fill up the pore in the structure and produce a more compact geopolymer body [10]. This make ladle furnace slag has betterpotential in improving the flexural strength of thin geopolymers than ground-granulated blast furnace slag. This paper studied the effect of ladle furnace slag replacement in the thin fly ash geopolymers. The paper focuesd on the correlation of the slag replacement ratio and the flexural properties of thin geopolymers.

\section{Methodology}

\section{Materials}

The aluminosilicate source of this study was fly ash collected from Manjung Coal-fired Power Plant, Malaysia. Ladle furnace slag (LFS) collected from Southern Steel Berhad Penang, Malaysia was partially replaced into thin fly ash geopolymers to investigate the effect of slag replacement. Table 1 depicts the chemical composition of fly ash and ladle furnace slag obtained via XRF analysis. The fly ash was made up of mainly $\mathrm{SiO}_{2}$ and $\mathrm{Al}_{2} \mathrm{O}_{3}$ of $56.30 \%$ and $28.00 \%$ respectively while the ladle furnace slag had the high amount of $\mathrm{CaO}$ wih the percentage of $63.59 \%$. The fly ash used was considered as Class F fly ash according to ASTM C618 as it consisted of only $3.89 \%$ of $\mathrm{CaO}$ which is less than $20 \%$. The SEM micrographs of fly ash and ladle furnace slag particle are shown in Figure 1. The fly ash particles had a spherical microstructure with smooth surfaces while ladle furnace slag has the microstructure of irregular and angular in shape and the grains are sharp-edged and partly dense. The alkaline activator used in this study was prepared by mixing the liquid sodium silicate $\left(\mathrm{Na}_{2} \mathrm{SiO}_{3}\right)$ with sodium hydroxide $(\mathrm{NaOH})$ solution. The chemical composition for liquid $\mathrm{Na}_{2} \mathrm{SiO}_{3}$ contained $60.5 \%$ of $\mathrm{H}_{2} \mathrm{O}, 30.1 \%$ of $\mathrm{SiO}_{2}$ and $9.4 \%$ of $\mathrm{Na}_{2} \mathrm{O}$ with $\mathrm{SiO}_{2} / \mathrm{Na}_{2} \mathrm{O}$ modulus of 3.2 , viscosity and specific gravity of 0.4 $\mathrm{Pa} \cdot \mathrm{s}$ and 1.4 respectively at $20^{\circ} \mathrm{C}$. Caustic soda pellets with the assay of $97.0 \%$ by the brand of $\mathrm{HmbG}^{\circledR}$ Chemicals was used to prepare the $\mathrm{NaOH}$ solution.

Table 1. Chemical composition of fly ash and ladle furnace slag

\begin{tabular}{lcccccccc}
\hline Composition & $\mathrm{SiO}_{2}$ & $\mathrm{Al}_{2} \mathrm{O}_{3}$ & $\mathrm{CaO}$ & $\mathrm{Fe}_{2} \mathrm{O}_{3}$ & $\mathrm{MgO}$ & $\mathrm{TiO}_{2}$ & $\mathrm{~K}_{2} \mathrm{O}$ & Others \\
\hline Fly Ash & 56.30 & 28.00 & 3.89 & 6.86 & - & 2.17 & 1.49 & 1.29 \\
\hline Ladle Furnace Slag & 21.30 & 2.30 & 63.59 & 8.08 & 2.60 & 0.50 & - & 1.63 \\
\hline
\end{tabular}




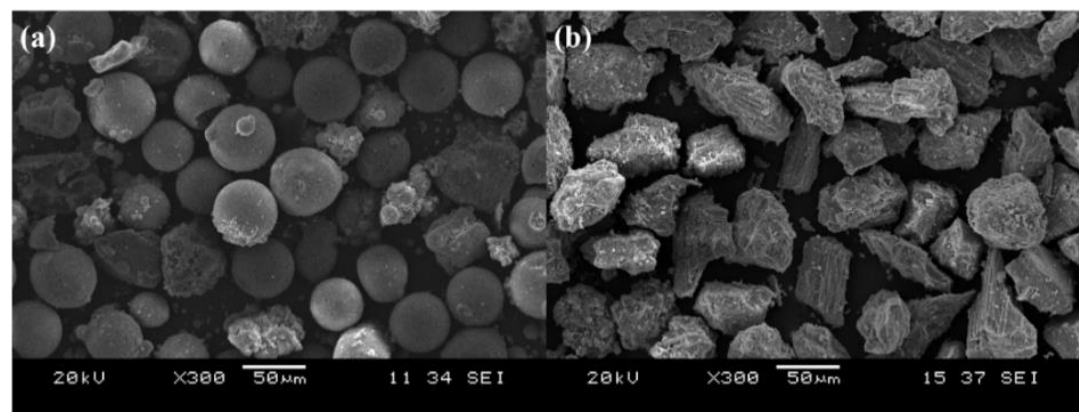

Fig. 1. Morphology of (a) fly ash and (b) ladle furnace slag under SEM

\section{Thin Geopolymer Formation}

The thin geopolymers were synthesised using $12 \mathrm{M} \mathrm{NaOH}, 2.5 \mathrm{~S} / \mathrm{L}$ ratio and 4.0 $\mathrm{Na}_{2} \mathrm{SiO}_{3} / \mathrm{NaOH}$ ratio. The percentage of ladle furnace slag substitute into fly ash was set as $10 \%$, $20 \%, 30 \%$ and $40 \%$. Fly ash and ladle furnace slag were mixed together with liquid alkali activator until homogenous slurry was achieved. Then, the slurry was rapidly poured into the moulds with dimension of $160 \times 40 \times 10 \mathrm{~mm}$ and compaction was done. The samples were then sent into oven with the curing temperature and time of $60^{\circ} \mathrm{C}$ and 6 hours. After that, the samples were cured at room temperature for another 24 hours. The cured thin geopolymers (Figure 2) were sealed with plastic wrap and kept for 28 days at room temperature before testing.

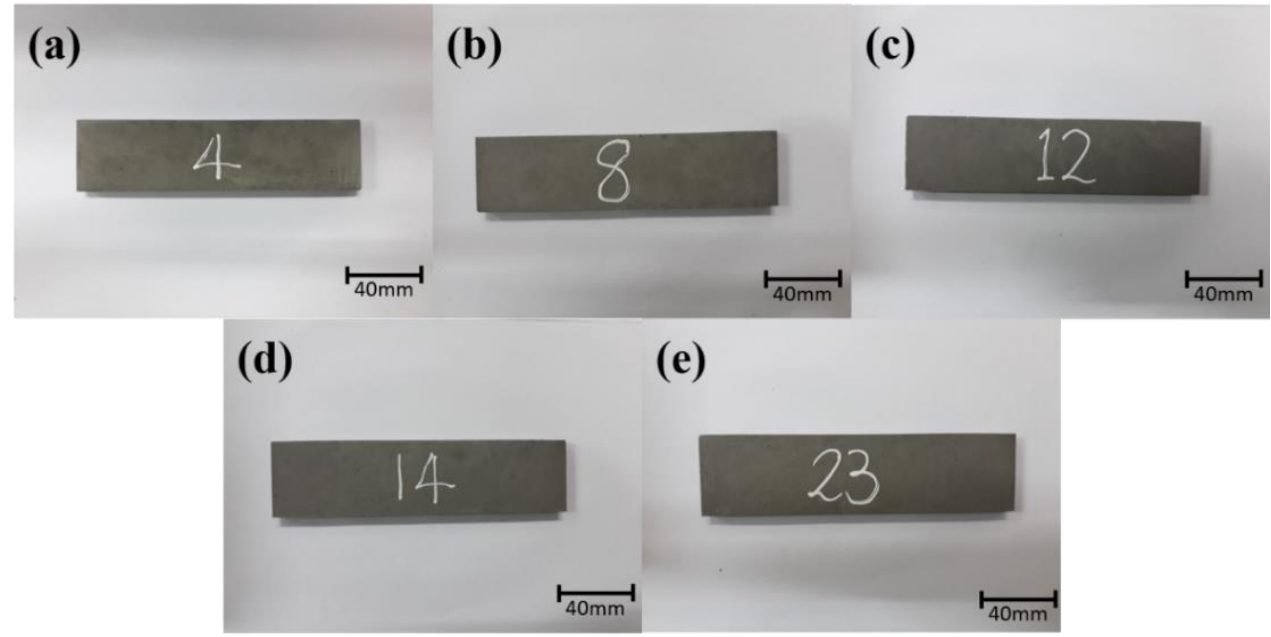

Fig. 2. Physical images of (a) thin fly ash geopolymers and fly ash/slag geopolymers replaced with (b) $10 \%$, (c) $20 \%$, (d) $30 \%$ and (e) $40 \%$ of ladle furnace slag

\section{Testing and Analysis}

Several testing and analyses were conducted to investigate the effect of ladle furnace slag replacement on the flexural properties of thin fly ash geopolymers. The bulk density of thin geopolymers were determined by measuring the mass and the dimensions of samples according to BS EN 12390-7. Water absorption was measured using the dry mass (heated in oven at $100^{\circ} \mathrm{C}$ for 24 hours) and wet mass (immersion of samples in water for 24 hours). Meanwhile, the apparent porosity was determined using the dry mass, wet mass and suspended mass (samples suspended in water after 24 hours immersion) in accordance to ASTM C642. Instron Machine Series 5569 Mechanical Tester was used to access the flexural strength of thin geopolymers using 
ASTM C348. The span length was fixed at $110 \mathrm{~mm}$ with $1 \mathrm{~mm} / \mathrm{min}$ crosshead speed. The microstructure of thin geopolymers at fracture surface was revealed using JSM-6460LA model Scanning Electron Microscope (JEOL). Model of D2 Phaser, Bruker X-Ray Diffractometer was used to access the phase of fly ash, slag and geopolymers with the scan range of $10-80^{\circ}$ and scan rate was $2^{\circ}$ per minute.

\section{Results and Discussion}

\section{Bulk Density, Apparent Porosity and Water Absorption}

Figure 3 displays the bulk density of thin fly ash/slag geopolymers with various percentages of ladle furnace slag replacement. In general, the fly ash/slag geopolymers has higher bulk density than the fly ash geopolymer and the bulk density of the samples increases as the slag replacement amount increases. This is because the density of ladle furnace $\operatorname{slag}\left(1238 \mathrm{~kg} / \mathrm{m}^{3}\right)$ is higher than fly ash $\left(1168 \mathrm{~kg} / \mathrm{m}^{3}\right)$. The highest bulk density recorded is fly ash/slag geopolymer replaced by $40 \%$ of ladle furnace slag which is $2273 \mathrm{~kg} / \mathrm{m}^{3}$ whereas the fly ash geopolymer possesses the lowest bulk density of $2060 \mathrm{~kg} / \mathrm{m}^{3}$. This can be explained by the fact that the incorporation of slag which is calcium-richleads to the formation of a denser microstructure [11]. Besides, Zawrah et al. [12] observed that different chemical reactions could occur with the incorporation of ladle furnace slag into the fly ash geopolymers system and thus produced different products as compared to fly ash geopolymers with no addition of slag. These different products caused the increment in bulk density and thus increased the strength development of geopolymers.

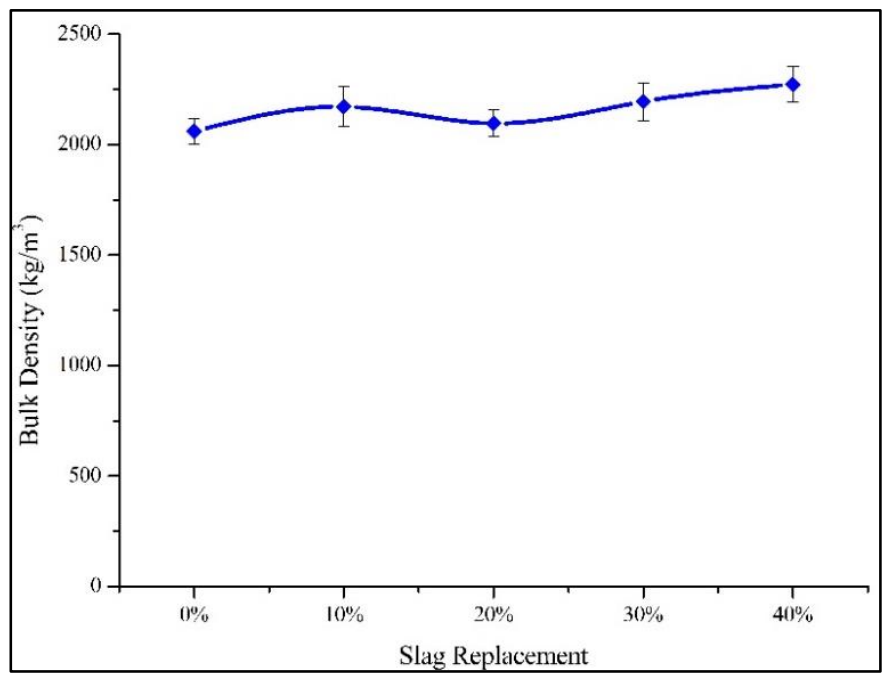

Fig. 3. Bulk density of thin fly ash/slag geopolymers with different percentages of ladle furnace slag replacement

Figure 4 illustrates the apparent porosity and water absorption of thin fly ash geopolymers partially replaced by different percentages of ladle furnace slag replacement. As the slag content increases, both the apparent porosity and water absorption decrease. Ghosh et al. [13] reported similar trend of decreasing in both apparent porosity and water absorption as slag content increased. They reported that the increase in slag content could favour the occurrence of different chemical reactions which led to different products formed in geopolymer system. $\mathrm{C}-\mathrm{A}-\mathrm{S}-\mathrm{H}$ gels which is more densified are formed and coexisted with the geopolymeric gel causes the decrease in water absorption and porosity [14]. Besides, the unreacted ladle furnace slag particles would 
act as a reinforcement and enhance the pore structure of the geopolymer matrix, which causes the porosity decreases and hence increases the strength of geopolymers [15].

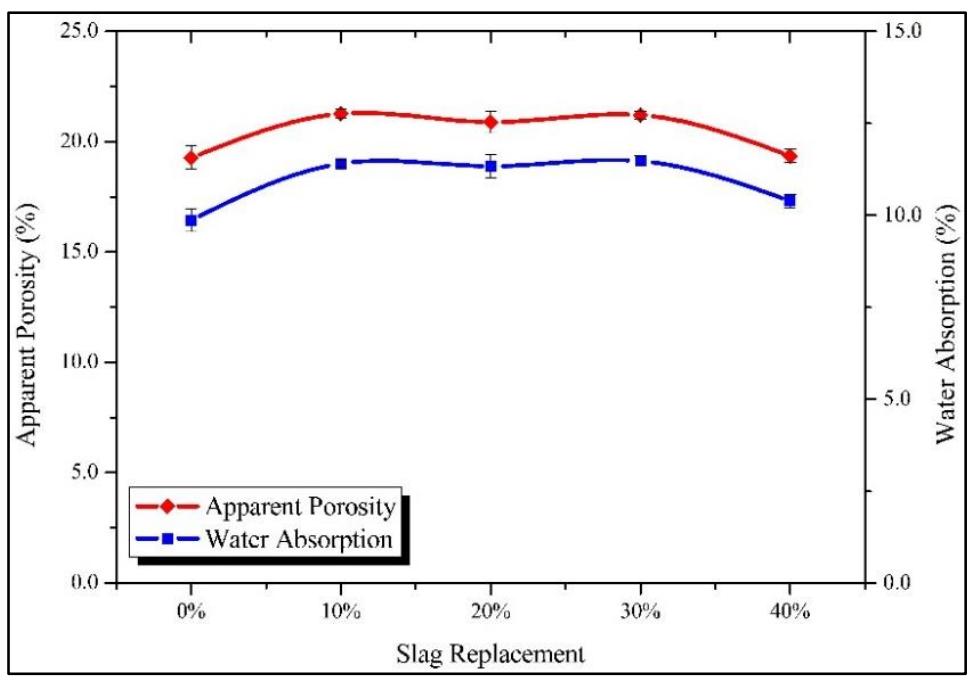

Fig. 4. Apparent porosity and water absorption of thin fly ash/slag geopolymers with different percentages of ladle furnace slag replacement

\section{Flexural Strength}

Figure 5 represents the flexural strength of thin fly ash/slag geopolymers with different percentages of ladle furnace slag replacement. Generally, thin fly ash/slag geopolymers possess higher flexural strength compare to thin fly ash geopolymer. This increment in flexural strength is contributed by the more reactive nature of slag particles. The improvement in flexural strength could be attributed to the incorporation of ladle furnace slag into the fly ash geopolymers. The highest flexural strength of $7.8 \mathrm{MPa}$ is obtained by the fly ash/slag geopolymer replaced by $40 \%$ of ladle furnace slag where it shows approximately $26 \%$ improvement of flexural strength as compared to the fly ash geopolymers with no slag replacement (6.2 MPa). Similar flexural trend was observed by Al-Majidi et al. [15] where they also reported that $40 \%$ of slag replacement contributed to the most increment in flexural strength. This could be related to the lowerreactivity nature of fly ash as compared to ladle furnace slag which normally had slower setting time and present a weaker strength $[16,17]$.

The high content of $\mathrm{CaO}$ from ladle furnace slag could improve the strength of geopolymers as the soluble $\mathrm{Ca}^{2+}$ ions are introduced into the geopolymer system, and facilitate the formation of C-S-H gel (Calcium Silicate Hydrate), C-A-S-H (Calcium Aluminosilicate Hydrate) gel alongside $\mathrm{N}-\mathrm{A}-\mathrm{S}-\mathrm{H}$ (Sodium Aluminosilicate Hydrate) gel [18-20]. The formation of these gels produced a more compact microstructure and has been reported to show an increment in the mechanical strength of geopolymers [21,22]. Kathirvel et al. [23] and Pilehvar et al. [24] investigated the effect of slag replacement on the properties of fly ash geopolymers. Through their investigations, they observed that the presence of $\mathrm{C}-\mathrm{S}-\mathrm{H}$ gels coexisted with the $\mathrm{N}-\mathrm{A}-\mathrm{S}-\mathrm{H}$ gels in the geopolymer matrix. These two species would promote the development of complex $\mathrm{C}-(\mathrm{N})-\mathrm{A}-\mathrm{S}-\mathrm{H}$ geopolymer gels. This complex species could accelerate the setting rate of geopolymers enhance the mechanical strength of geopolymers. Similar trends were observed by Khale and Chaudhary [25] as the strength of fly ash/slag geopolymers increased with the C(N) $-\mathrm{A}-\mathrm{S}-\mathrm{H}$ gels formation from the higher slag amount, which caused the porosity decreased and favoured the densification in the geopolymers' microstructure. 
On the other hand, a slight decrement in the flexural strength could be observed in the fly ash/slag geopolymer replaced with $20 \%$ of ladle furnace slag as compared to other percentages of slag replacement. However, the flexural strength is still higher as compared to the fly ash geopolymer with no slag replacement. It is believed that the drop in strength is related to the bulk density and porosity of the fly ash/slag geopolymer as the flexural strength results obtained is in aligned with the bulk density and apparent porosity obtained in Figure 4, respectively. Lower bulk density exhibits a looser geopolymeric structure with pores and thus shows lower value of flexural strength.

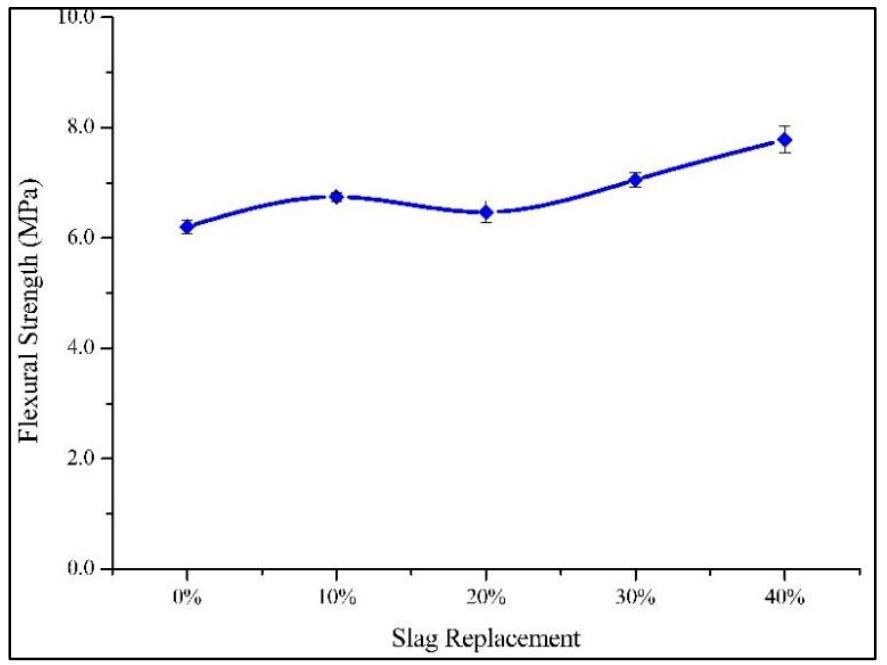

Fig. 5. Flexural strength of thin fly ash/slag geopolymers with different percentages of ladle furnace slag replacement

\section{Microstructural Analysis}

Figure 6 shows the microstructure of the fracture surface of fly ash/slag geopolymers replaced with different amount of ladle furnace slag under SEM. As the slag amount increases from $10 \%$ to $40 \%$, more densified and compact structure is observed with the formation of more $\mathrm{C}-\mathrm{S}-\mathrm{H}$ gel coexists with the geopolymer matrix. Figure 7 depicts the SEM micrograph of C-S$\mathrm{H}$ gel present in fly ash geopolymer replaced by $40 \%$ ladle furnace slag with $2000 \times$ magnification. Zawrah et al. [12] observed the same phenomena in the microstructure of geopolymers with increasing slag content. They reported that increasing the slag content exhibited more $\mathrm{C}-\mathrm{S}-\mathrm{H}$ gel as dominant products and coexisted with geopolymeric gel, and hence produced a more compact microstructure which could enhance the strength of geopolymer.

Furthermore, the increasing amount of $\mathrm{CaO}$ from slag reduced the microstructural porosity as more amorphous structure $\mathrm{Ca}-\mathrm{Al}-\mathrm{Si}$ gels were formed [26, 27]. This complied with the apparent porosity results obtained in Figure 4 in which the fly ash/slag geopolymers have lower porosity than the fly ash geopolymers with no slag replacement. Murri et al. [28] observed that the fly ash/ ladle furnace slag geopolymers with higher $\mathrm{CaO}$ content had denser matrices and lesser number of unreacted spherical fly ash particles. Besides, Phair et al. [29] stated that the increasing slag content promoted polysialate network formation and hardening of the geopolymer matrix. The substitution of slag into fly ash geopolymers could accelerate the reaction rate and promote strength development as the reactivity of fly ash is relatively slow at room temperature [30]. Hence, the flexural strength of thin fly ash geopolymers improved with the substitution of slag into the system as shown in Figure 5. 

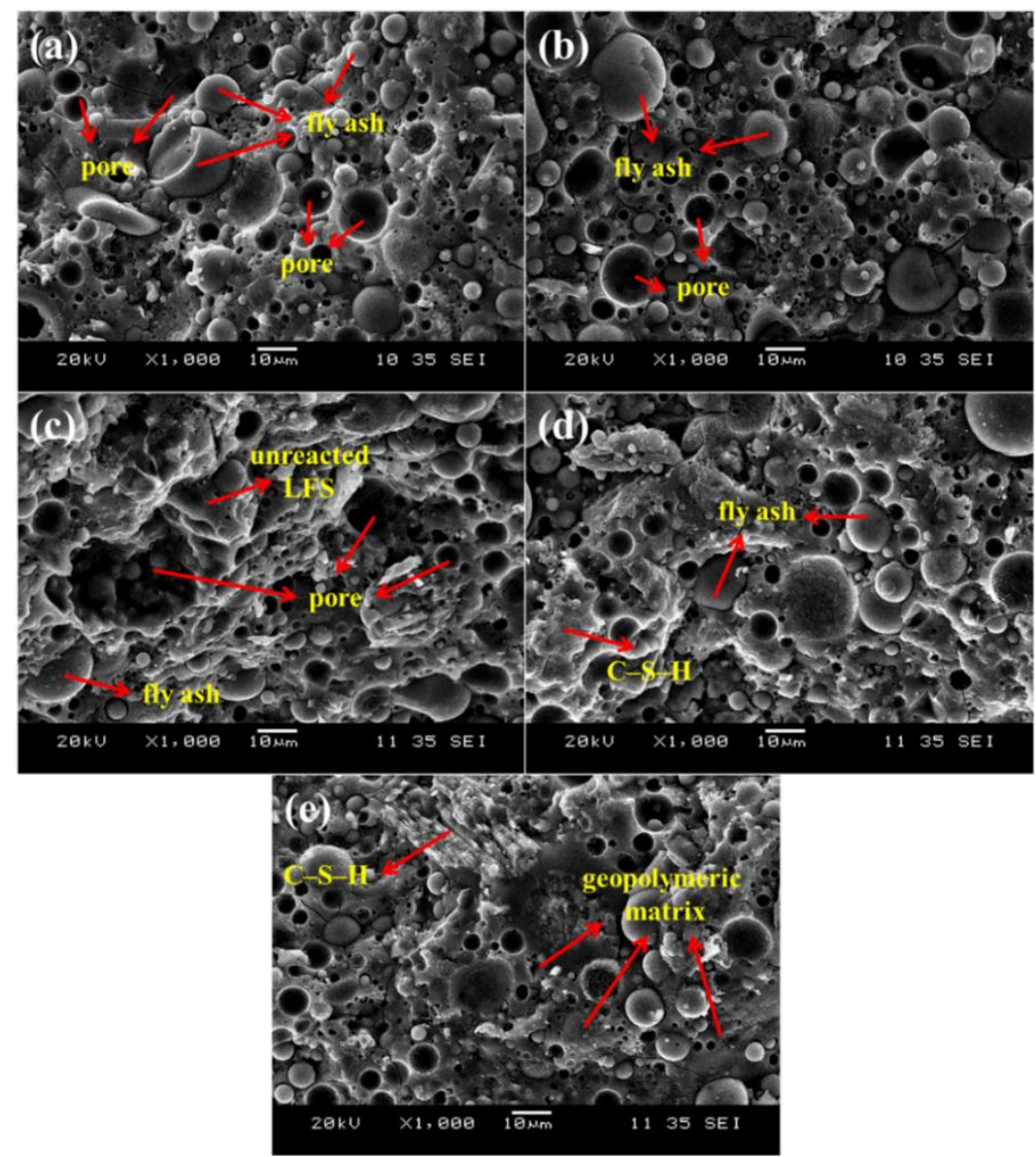

Fig. 6. Fracture surface of (a) fly ash geopolymers and fly ash/slag geopolymers replaced with (b) $10 \%$, (c) $20 \%$, (d) $30 \%$ and (e) $40 \%$ of ladle furnace slag under SEM

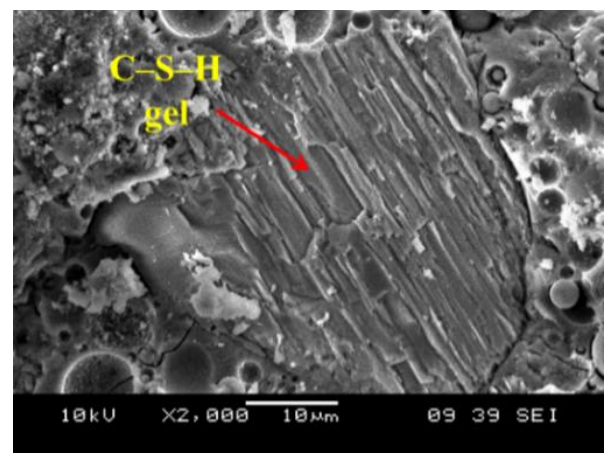

Fig. 7. SEM micrograph of C-S-H gel formation in fly a sh/slag geopolymer substituted with $40 \%$ of ladle furnace slag

In addition, Qiu et al. [31] reported that more geopolymerisation products were produced in the samples with higher slag content. In contrast, higher amount of fly ash produces a rather loose matrix. From Figure 6 (a) to (c), a more loosely packed structures with large amount of 
partially-reacted or unreacted fly ash and slag particles are observed. Besides, more pores are observed when compared to the higher amount of slag replacement (Figure $6 \mathrm{~d}$ and e).

\section{Phase Analysis}

Figure 8 displays the XRD pattern of fly ash and ladle furnace slag using X-ray diffractogram. Based on Figure 8(a), there is a broad hump of diffraction in fly ash between $15^{\circ}$ and $35^{\circ}$ indicating the amorphous phases of fly ash [32]. Fly ash showed an intense diffraction peak of quartz $\left(\mathrm{SiO}_{2}\right)$ with other diffraction peaks of mullite $\left(3 \mathrm{Al}_{2} \mathrm{O}_{3} \cdot 2 \mathrm{SiO}_{2}\right)$ and hematite $\left(\mathrm{Fe}_{2} \mathrm{O}_{3}\right)$. For ladle furnace slag, the intense peak of belite $\left(\mathrm{Ca}_{2} \mathrm{SiO}_{4}\right)$ was observed with the presence of glassy phase of larnite $\left(\mathrm{Ca}_{2} \mathrm{SiO}_{4}\right)$, merwinite $\left(\mathrm{Ca}_{3} \mathrm{MgSi}_{2} \mathrm{O}_{8}\right)$, magnetite $\left(\mathrm{Fe}_{3} \mathrm{O}_{4}\right)$ and calcium aluminium oxide $\left(\mathrm{CaAl}_{2} \mathrm{O}_{4}\right)$.

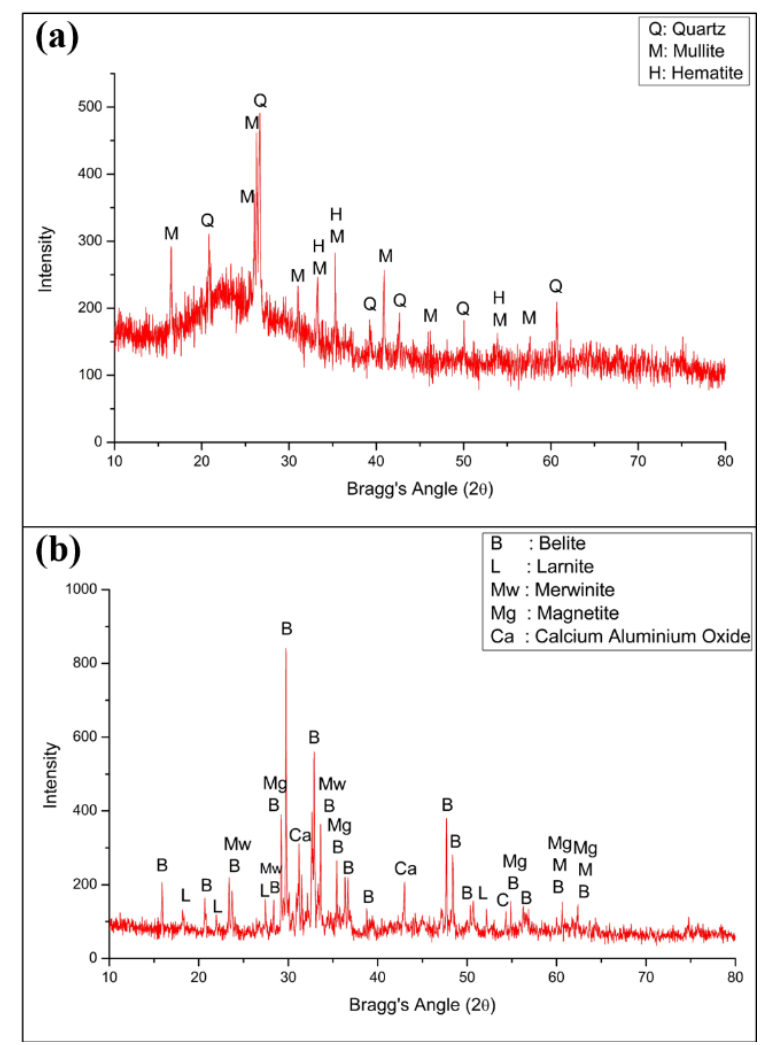

Fig. 8. XRD pattern of (a) fly ash and (b) ladle furnace slag

Figure 9 displays the XRD diffractogram of fly ash/slag geopolymers replaced with various percentages of ladle furnace slag. It could be observed that fly ash geopolymers have the major peaks of quartz $\left(\mathrm{SiO}_{2}\right)$ and mullite $\left(3 \mathrm{Al}_{2} \mathrm{O}_{3} \cdot 2 \mathrm{SiO}_{2}\right)$. The vitreous phase of the original ash, which is represented by the broad hump, shifted slightly from $15-30^{\circ}$ to $20-40^{\circ}(2 \theta)$ values. The alkaline activation of ladle furnace slag causes the geopolymerisation process accelerates and some new phases that could contribute to the strength development of are formed. Secondary peaks of belite $\left(\mathrm{Ca}_{2} \mathrm{SiO}_{4}\right)$, calcium silicate hydrate $(\mathrm{C}-\mathrm{S}-\mathrm{H})$ gel and calcite $\left(\mathrm{CaCO}_{3}\right)$ are observed as the slag amount increases [33]. Previous studies also observed that the main binding phase of alkali-activated slag materials is $\mathrm{C}-\mathrm{S}-\mathrm{H}$ gels [34]. These peaks appear along with the primary peaks of quartz and mullite. Besides, the intensity of the broad hump reduces with increasing slag 
amount. This is because more crystalline phases are formed associated with the rich amount of calcium in slag [35].

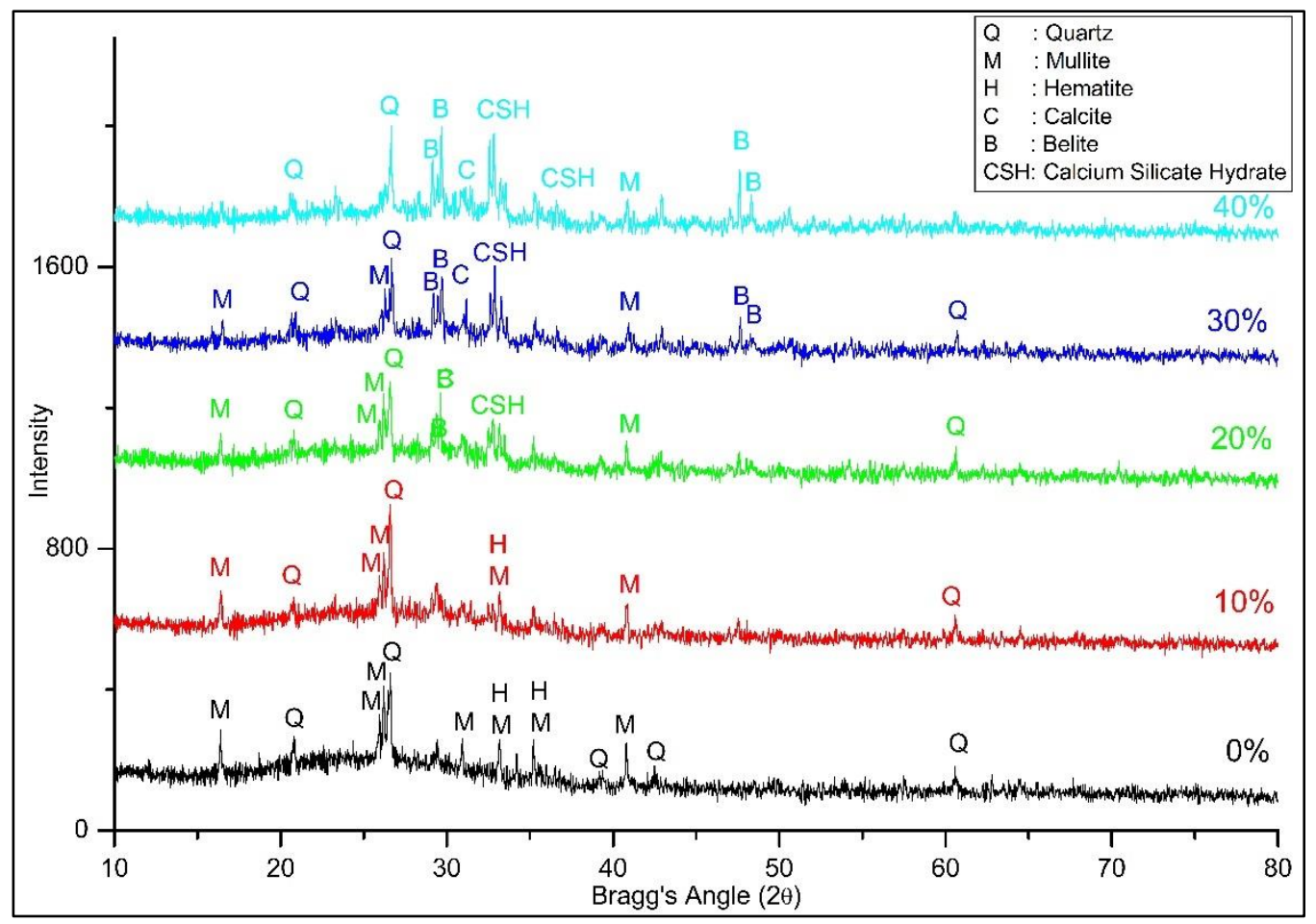

Fig. 9. XRD diffractogram of fly a sh/slaggeopolymers with different percentages of ladle furnace slag replacement

Besides that, the intensity of quartz and mullite decreases and even disappears when the percentage of slag replacement increases from $10 \%$ to $40 \%$. The peak intensity for $\mathrm{C}-\mathrm{S}-\mathrm{H}$ gel and calcite becomes more apparent due the alkali activation of slag. The high $\mathrm{CaO}$ content promoted the $\mathrm{C}-\mathrm{S}-\mathrm{H}$ gel development of and the excess $\mathrm{CaO}$ would react with $\mathrm{CO}_{2}$ to form calcite [36]. The high intensity of belite is attributed from the major phase present in the ladle funace slag as shown in Figure 8. Apart from that, the highest intensity of $\mathrm{C}-\mathrm{S}-\mathrm{H}$ gel and calcite could be observed in the fly ash/slag geopolymer replaced by $40 \%$ of ladle furnace slag. The coexistence of belite, calcite and $\mathrm{C}-\mathrm{S}-\mathrm{H}$ gel alongside with aluminosilicate gel helped improving the mechanical properties of geopolymers [19]. This observation is in parallel with the flexural strength data obtained in Figure 5.

\section{Conclusion}

This paper studied the effect of ladle furnace slag replacement on the flexural properties of thin fly ash geopolymers. Correlation of physical and flexural properties of thin fly ash/slag geopolymers was made viabulk density measurement, apparent porosity and flexural test. Results obtained showed that the amount of slag replacement plays a significant role in improving the flexural properties of thin fly ash geopolymers as the flexural strength of geopolymers increased as the amount of slag replacement increased. The thin fly ash geopolymers were replaced with $40 \%$ of ladle furnace slag was observed to have the highest flexural strength of 7.8 MPa. The $\mathrm{CaO}$ present in theladle furnace slag eased the $\mathrm{C}-\mathrm{S}-\mathrm{H}$ gels formation in the geopolymer structure. This $\mathrm{C}-\mathrm{S}-\mathrm{H}$ gels formation produced a more compact microstructure which could be observed 
in the SEM micrographs helps improved the flexural strength of thin geopolymers. XRD results also further proved that the flexural properties of thin fly ash geopolymers was enhanced by the higher amount of slag.

\section{Acknowledgements}

The authors wish to acknowledge Manjung Coal-fired power plant Perak, Malaysia and Southern Steel Berhad Penang, Malaysia for supplying the aluminosilicates sources of class F fly ash and ladle furnace slag, respectively for this research.

The authors of the present work wish to acknowledge the funding support from "Partnership for Research in Geopolymer Concrete" (H2020-MSCA-RISE-2015-689857PRIGeoC) sponsored by the European Union.

\section{References}

[1] J. Davidovits, Geopolymers: Ceramic-like inorganic polymers, J. Ceram. Sci. Technol., 8(3), 2017, pp. 335-350.

[2] A.F. Abdalqader, F. Jin, A. Al-Tabbaa, Development of greener alkali-activated cement: utilisation of sodium carbonate for activating slag and fly ash mixtures, J. Cleaner Prod., 113, 2016, pp. 66-75.

[3] F. Fan,Z. Liu, G. Xu, H. Peng, C.S. Cai, Mechanical andthermal properties offly ash based geopolymers, Constr. Build. Mater., 160, 2018, pp. 66-81.

[4] G.F. Huseien, J. Mirza, M. Ismail, S.K. Ghoshal, A.A. Hussein, Geopolymer mortars as sustainable repair material: A comprehensive review, Renewable Sustainable Energy Rev., 80, 2017,pp. 54-74.

[5] S.A. Bernal, R.M. de Gutiérrez, J.L. Provis, Engineering and durability properties of concretes based on alkali-activated granulated blast furnace slag/metakaolin blends, Constr. Build. Mater., 33, 2012, pp. 99-108.

[6] K. Sankar, P. Stynoski, G.K. Al-Chaar, W.M. Kriven, Sodium silicate activated slag-fly ash binders: Part I - Processing, microstructure, and mechanical properties, J. Am. Ceram. Soc., 101(6), 2018, pp. 2228-2244.

[7] M. Chi, R.Huang, Binding mechanism and properties of alkali-activated fly ash/slag mortars, Constr. Build. Mater., 40, 2013, pp. 291-298.

[8] S. Puligilla, P. Mondal, Role of slag in microstructural development and hardening offly ash-slag geopolymer, Cem. Concr. Res., 43, 2013, pp. 70-80.

[9] P. Nath, P.K. Sarker, Flexural strength and elastic modulus of ambient-cured blended lowcalciumfly ash geopolymer concrete, Constr. Build. Mater., 130, 2017, pp. 22-31.

[10] A. Rađenović, J. Malina, T. Sofilić, Characterization ofladle furnace slag from carbon steel production as a potential adsorbent, Adv. Mater.Sci.Eng., 2013, 2013, Article ID 198240.

[11] G. Kushal, G. Partha, Effect of variation of sodium silicate content on microstructure and mechanical properties of thermally cured fly ash-slag based geopolymer composites, Res. J. Chem. Environ, 23, 2019, pp. 1-9.

[12] M. Zawrah, R. Gado, R. Khattab, Optimization of slag content and properties improvement of metakaolin-slag geopolymermixes, Open Mater Sci J, 12(1), 2018, pp 40-57.

[13] K. Ghosh, P. Ghosh, Effect of variation of slag content on chemical, engineering and microstructural properties of thermally cured fly ash-slag based geopolymer composites, Rasayan J. Chem., 11(1), 2018, pp. 426-439. 
[14] I. Niklioć, S. Marković, I. Janković-Častvan, V.V. Radmilović, L. Karanović, B. Babić, V.R. Radmilović, Modification of mechanical and thermal properties of fly ash-based geopolymer by the incorporation of steel slag, Mater. Lett., 176, 2016, pp. 301-305.

[15] M.H. Al-Majidi, A. Lampropoulos, A. Cundy, S. Meikle, Development of geopolymer mortar under ambient temperature for in situ applications, Constr. Build. Mater., 120, 2016, pp. 198-211.

[16] A.V. Kirschner, H. Harmuth, Investigation of geopolymer binders with respect to their application for building materials, Ceram. Silik., 48(3), 2004, pp. 117-120.

[17] R. Junru, C. Huiguo, D. Ruixi, S. Tao, Behavior of combined fly ash/GBFS-based geopolymer concrete after exposed to elevated temperature, IOP Conference Series: Earth and Environmental Science, 267, May 2019, p. 032056.

[18] S. Kumar, R. Kumar, S.P. Mehrotra, Influence of granulated blast furnace slag on the reaction, structure and properties offly ash based geopolymer, J. Mater. Sci., 45(3), 2010, pp. 607-615.

[19] I. Ismail, S.A. Bernal, J.L. Provis, R.S. Nicolas, S. Hamdan, J.S.J. van Deventer, Modification of phase evolution in alkali-activated blast furnace slag by the incorporation offly ash, Cem. Concr. Compos., 45, 2014, pp. 125-135.

[20] F.U.A. Shaikh, Effects of slag content on the residual mechanical properties of ambient aircured geopolymers exposed to elevated temperatures, J. Asian Ceram. Soc., 6(4), 2018, pp. 342-358.

[21] S. Saha, C. Rajasekaran, Enhancement of the properties offly ash based geopolymer paste by incorporating ground granulated blast furnace slag, Constr. Build. Mater., 146, 2017, pp. 615-620.

[22] A.E. Kurtoğlu, R. Alzeebaree, O. Aljumaili, A. Niş1 1c, Mechanical and durabilityproperties offly ash and slag based geopolymer concrete, Adv. Concr. Constr., 6(4), 2018, pp 345.

[23] P. Kathirvel, K. Saravanarajamohan, S. Shobana, A. Bhaskar, Effect of replacement of slag on the mechanical properties of flyash based geopolymer concrete, Int. J. Eng. Sci. Technol., 5(3), 2013, pp 2555-2559.

[24] S. Pilehvar, V.D. Cao, A.M. Szczotok, M. Carmona, L. Valentini, M. Lanzón, R. Pamies, A.L. Kjøniksen, Physical and mechanical properties of fly ash and slag geopolymer concrete containing different types of micro-encapsulated phase change materials, Constr. Build. Mater., 173, 2018, pp. 28-39.

[25] D. Khale, R. Chaudhary, Mechanism of geopolymerization and factors influencing its development: a review, J. Mater. Sci., 42(3), 2007, pp. 729-746.

[26] H. Ye, A. Radlińska, Fly ash-slag interaction during alkaline activation: Influence of activators on phase assemblage andmicrostructure formation. Constr.Build. Mater., 122, 2016, pp. 594-606.

[27] T. Yang, H. Zhu, Z. Zhang, X. Gao, C. Zhang, Q. Wu, Effect offly ash microsphere on the rheology and microstructure of alkali-activated fly ash/slag pastes, Cem.Concr.Res., 109, 2018, pp. 198-207.

[28] A.N. Murri, W.D.A. Rickard, M.C. Bignozzi, A. van Riessen, A., High temperature behaviour of ambient cured alkali-activated materials based on ladle slag, Cem. Concr. Res., 43, 2013, pp. 51-61.

[29] J.W. Phair, J.S.J. van Deventer, Effect of silicate activator $\mathrm{pH}$ on the leaching and material characteristics of waste-based inorganic polymers, Miner. Eng., 14(3), 2001, pp. 289-304.

[30] S. Samantasinghar, S.P. Singh, Effect of synthesis parameters on compressive strength of fly ash-slag blended geopolymer, Constr. Build. Mater., 170, 2018, pp. 225-234. 
[31] J. Qiu, Y. Zhao, J. Xing, X. Sun, X., Fly ash/blast furnace slag-based geopolymer as a potential binder for mine backfilling: Effect of binder type and activator concentration, Adv. Mater.Sci. Eng., 2019, 2019, pp 1-12.

[32] S. Kramar, V. Ducman, Mechanical and microstructural characterization of geopolymer synthesized from low calciumfly ash, Chem. Ind. Chem. Eng.Q., 21(1-1), 2015, pp. 13-22.

[33] T. Phoo-ngernkham, A. Maegawa, N. Mishima, S. Hatanaka, P. Chindaprasirt, Effects of sodium hydroxide and sodium silicate solutions on compressive and shear bond strengths of FA-GBFS geopolymer, Constr. Build. Mater., 91, 2015, pp. 1-8.

[34] S. Puligilla, X. Chen, X., P. Mondal, Does synthesized C-S-H seed promote nucleation in alkali activated fly ash-slag geopolymer binder?, Mater. Struct., 52(4), 2019, pp. 65.

[35] X. Wan, D. Hou, T. Zhao, L. Wang, Insights on molecular structure and micro-properties of alkali-activated slag materials: A reactive molecular dynamics study, Constr. Build. Mater., 139, 2017, pp. 430-437.

[36] D. Ravikumar, S. Peethamparan, N. Neithalath, Structure and strength of NaOH activated concretes containing fly ash or GGBFS as the sole binder, Cem. Concr. Compos., 32(6), 2010, pp. 399-410.

Received: June 03, 2020

Accepted: July 09, 2020 